\title{
Dysmagnesemia in Covid-19 cohort patients: prevalence and associated factors
}

\author{
Didier Quilliot $^{1}$, Olivier Bonsack ${ }^{1}$, Roland Jaussaud ${ }^{2}$, André Mazur ${ }^{3}$ \\ ${ }^{1}$ Transversal Nutrition Unit and; ${ }^{2}$ Internal Medicine and Clinical Immunology. Nancy \\ University Hospital, University of Lorraine, France; ${ }^{3}$ Université Clermont Auvergne, \\ INRAE, UNH, Unité de Nutrition Humaine, Clermont-Ferrand, France \\ Correspondence \\ $<$ d.quilliot@chru-nancy.fr>
}

\begin{abstract}
Hypomagnesemia and hypermagnesemia could have serious implications and possibly lead to progress from a mild form to a severe outcome of Covid-19. Susceptibility of subjects with low magnesium status to develop and enhance this infection is possible. There is little data on the magnesium status of patients with Covid-19 with different degrees of severity. This study was conducted to evaluate prevalence of dysmagnesemia in a prospective Covid-19 cohort study according to the severity of the clinical manifestations and to identify factors associated.

Serum magnesium was measured in 300 of 549 patients admitted to the hospital due to severe Covid-19. According to the WHO guidelines, patients were classified as moderate, severe, or critical. $48 \%$ patients had a magnesemia below $0.75 \mathrm{mmol} / \mathrm{L}$ (defined as magnesium deficiency) including $13 \%$ with a marked hypomagnesemia $(<0.65 \mathrm{mmol} / \mathrm{L}) .9 .6 \%$ had values equal to or higher than 0.95 $\mathrm{mmol} / \mathrm{L}$. Serum magnesium concentrations were significantly lower in female than in male $(0.73 \pm 0.12$ vs $0.80 \pm 0.13 \mathrm{mmol} / \mathrm{L})$, whereas the sex ratio $\mathrm{M} / \mathrm{F}$ was higher in severe and critical form $(\mathrm{p}<0.001)$. In a bivariate analysis, the risk of magnesium deficiency was significantly and negatively associated with infection severity $(\mathrm{p}<0.001)$, sex ratio $(\mathrm{M} / \mathrm{F}, \mathrm{p}<0.001)$, oxygenotherapy $(\mathrm{p}<0.001)$, stay in critical care unit $(\mathrm{p}=0.028)$, and positively with nephropathy $(p=0.026)$. Logistic regression analysis revealed that the strongest predictors of magnesium deficiency were female sex $(\mathrm{OR}=2.67, \mathrm{p}<0.001)$ and nephropathy $(\mathrm{OR}=2.12, \mathrm{p}=0.032)$ and after exclusion of sex ratio, the severity of infection $(\mathrm{OR}=0.46, \mathrm{p}=0.04$ and $\mathrm{OR}=0.39 \mathrm{p}=0.01)$, for critical and moderate forms, respectively. This transversal study reveals a high prevalence of hypomagnesemia in hospitalized patients for Covid-19, while high-level serum magnesium concentration was more prevalent in critical form.
\end{abstract}

Key words: magnesium, Covid-19, disease severity, patients

Magnesium, an essential mineral for basic biochemical reactions, participates in a cluster of normal physiological functions and metabolism, such as the transport of potassium and calcium ions across cell membranes [1,2], energy metabolism, protein and nucleic acid synthesis [3]. Among its various functions, magnesium has an anti-inflammatory action, and plays a role in the immune response, antioxidant protection, and vasodilation [4-6]. A large proportion of western countries' population does not meet the recommended daily

\section{4}

To cite this article: Quilliot D, Bonsack O, Jaussaud R, Mazur A. Magnes Res 2020; 33(4): 114-122. doi: 10.1684/mrh.2021.0476 
magnesium requirement. Several chronic diseases associate low magnesium status, e.g., diabetes, metabolic syndrome, hypertension, and coronary artery disease. It is proposed that the low magnesium status can contribute to the development or progression of these pathologies $[4,7,8]$.

In hospitalized patients hypomagnesemia frequently occurs with other electrolyte disorders and might have a role in the worsening of the diseases [9]. In a large cohort of 65,974 patients [10] hospitalized in the Mayo Clinic, hypermagnesemia had the most independent influence on worse patient outcomes. Reduced survival was noted in patients with both low and high magnesium levels. The highest magnesium range ( $>0.95 \mathrm{~mol} / \mathrm{L})$, however, was the strongest independent predictor of hospital mortality. Recently, other retrospective studies also provide the data on the occurrence of dysmagnesemia in patients according to the gender, age, and result of hospitalization $[11,12]$.

Hypomagnesemia is commonly seen [13-15] in intensive care unit (ICU) patients and appears associated with greater risk of mortality, sepsis, mechanical ventilation, and the length of ICU stay [16, 17]. In ICU, a retrospective study [18] shows that patients with hypermagnesemia at admission were at two-fold increased crude risk for death than those with normal levels. Lastly, in community-acquired pneumonia, high normal magnesium levels (between 0.82$0.99 \mathrm{mmol} / \mathrm{L}$ ) have been correlated with higher 30-day mortality rates. Therefore, these paradoxical results show that both hypo- and hypermagnesemia could be associated with a pejorative prognosis [19].

During coronavirus disease 2019 (Covid-19), hypomagnesemia could have serious implications and possibly lead to progress from mild form to a severe outcome of the disease. In fact, magnesium deficiency may induce a drop of $\mathrm{T}$ cells, increase plasma concentration of inflammatory cytokines, and endothelial dysfunction $[5,20]$. The question arises about the higher susceptibility of subjects with low magnesium status to develop and enhance this infection. This may mostly concern people with comorbidities (diabetes, obesity, organ failures, etc.) and the elderly. However, data about the magnesium status during the Covid-19 are scarce [20-23].
This study was conducted to evaluate prevalence of dysmagnesemia in a prospective Covid-19 cohort study according to the severity of the infection.

\section{Methods}

\section{Study design and participants}

This study, conducted as part of a prospective cohort study, included all adult inpatients ( $\geq 18$ years old) who were diagnosed with COVID-19 admitted in an ICU or non-ICU unit for COVID-19 patients at the Nancy Brabois University Hospital between March 1, 2020 and April 29, 2020. The diagnosis of COVID-19 was based on a positive SARS-Cov-2 RT-PCR test on a nasopharyngeal sample and/or on a CT chest scan [24]. The study was approved by the Research Commission of the University Hospital of Nancy and the requirement for informed consent was waived by the ethics commission. ClinicalTrials.gov Identifier is NCT04451694.

According to the WHO guidelines [25], patients were classified as follows: Moderate, fever, and respiratory symptoms with radiological findings of pneumonia and risk factors; Severe, respiratory distress ( $\geqq 30$ breaths/ min), or oxygen saturation $\leq 93 \%$ at rest, or arterial partial pressure of oxygen $(\mathrm{PaO} 2) /$ fraction of inspired oxygen ( $\mathrm{FiO} 2)$ $\leqq 300 \mathrm{mmHg}$, or lesion progression within 24-48 hours $>50 \%$ by chest imaging; critical cases, respiratory failure and requiring mechanical ventilation, or shock, or other organ failure that requires ICU care.

None of these patients had a magnesium supplementation before blood analysis.

\section{Demographics, comorbidities, and hospitalization data}

Patient characteristics and hospitalization data were collected by manual review of electronic medical records. Epidemiological, demographic, laboratory, and outcome data were extracted from electronic medical records during hospitalization.

Demographic data included age, sex. Health characteristics included comorbidities: hypertension, diabetes mellitus, cerebrovascular disease, cardiovascular disease, chronic lung 
disease, as well as the symptoms of COVID-19 (anosmia and dysgeusia, diarrhea, dyspnea, asthenia, food aversion). Hospitalization characteristics included: ICU admission (yes/no), time between symptom onset and hospitalization (days), length of stay (days).

\section{Serum Magnesium}

Colorimetric assay using xylidyl blue-based reagent was performed on a clinical chemistry analyzer (Atellica CH, Siemens Healthineers, St Denis, France).

Serum magnesium data were extracted from electronic medical records during hospitalization. Given the reference range for serum magnesium concentration between 0.85 and $0.95 \mathrm{mmol} / \mathrm{L}$, to assess the frequency and extent of low and high magnesemia in the subjects studied, we used different cut-off values, lower than $0.65,0.75$, and $0.85 \mathrm{mmol} / \mathrm{L}$ and equal to or higher than 0.95 , or $1.05 \mathrm{mmol} / \mathrm{L}$. Results are presented using these cutoffs or as a distribution of individual magnesium concentrations.

Taking into account all the more recent investigations [26] about serum magnesium, $0.65 \mathrm{mmol} / \mathrm{L}$ reveals severe deficiency and 0.75 $\mathrm{mmol} / \mathrm{L}$ the limit of deficiency. According to the recent studies on clinical data $[10,18,19]$, hypermagnesemia was defined by a cutoff equal to or over than $0.95 \mathrm{mmol} / \mathrm{L}$ and $1.05 \mathrm{mmol} / \mathrm{L}$.

\section{Statistical analysis}

Continuous variables are expressed as mean $\pm \mathrm{SD}$ and categorical variables as absolute values and percentages. Paired Student's t-test, chi-square, ANOVA, Fisher's exact test, and Kruskal-Wallis tests were used to compare values of variables between groups, as appropriate. Pearson's chi-square $(\chi 2)$ test or Fisher's exact test was used to assess the association between each of the discrete variables and patients' magnesium status. Variables significant at a 0.05 level were subsequently used in multivariate analyses. Data were recorded on Excel files. Factors associated with hypomagnesemia were investigated by using a logistic regression model with a stepwise selection method. Statistical analysis was performed using Statistical Analysis Software 9.4, SAS Institute Inc, Cary, North Carolina, USA.

\section{Results}

From March 1, 2020 to April 29, 2020, 549 patients were admitted to hospital due to severe COVID-19, including 63/549 (11.5\%) who were

Table 1. Basic characteristics of studied patients affected by Covid-19 and mean serum magnesemia, creatininemia, inflammatory factors, D-dimer, and albuminemia.

\begin{tabular}{|c|c|c|c|c|c|}
\hline & Mean (SD) & median [Q25-75] & $\min$ & $\max$ & $\mathbf{n}$ \\
\hline Age at admission (years) & $66.7(16.3)$ & $68.0[57.0 ; 77.0]$ & 18.0 & 101 & 298 \\
\hline Sex ratio & $183 \mathrm{M} / 117 \mathrm{~F}$ & & & & \\
\hline Serum magnesium (mmol/L) & $0.78(0.13)$ & $0.78[0.70 ; 0.86]$ & 0.45 & 1.27 & 300 \\
\hline BMI $\left(\mathrm{Kg} / \mathrm{m}^{2}\right)$ & $27.8(6.05)$ & $27.2[23.7 ; 31.5]$ & 15.8 & 50.1 & 201 \\
\hline Creatininemia $(\mathrm{mg} / \mathrm{L})$ & $10.1(12.7)$ & $7.00[5.00 ; 10.0]$ & 1.00 & 165 & 300 \\
\hline Albuminemia (g/L) & $28.5(5.59)$ & $29.0[25.0 ; 32.0]$ & 13.0 & 45.0 & 292 \\
\hline D-dimer $(\mu \mathrm{g} / \mathrm{L})$ & $2747(2490)$ & $1755[1099 ; 3480]$ & 249 & 10000 & 188 \\
\hline Fibrinogen (g/L) & $6.91(1.90)$ & $6.90[5.80 ; 8.20]$ & 1.70 & 12.0 & 235 \\
\hline Lymphocytemia $\left(\mathrm{X1000/ \textrm {mm } ^ { 3 } )}\right.$ & $0.957(0.586)$ & $0.860[0.560 ; 1.20]$ & 0.0600 & 5.54 & 296 \\
\hline CRP (mg/L) & $152(96.8)$ & $134[83.8 ; 212]$ & 0 & 494 & 264 \\
\hline Thrombocytemia $\left(\mathrm{X1000/} \mathrm{mm}^{3}\right)$ & $225(107)$ & $212[149 ; 281]$ & 5.00 & 660 & 298 \\
\hline NT-proBNP (ng/L) & $3685(10531)$ & $779[180 ; 2476]$ & 0 & 113936 & 231 \\
\hline
\end{tabular}

CRP: C reactive Protein; BMI: Body Mass Index; NT-proBNP: N-terminal pro-B-type natriuretic peptide. 
discharged to another hospital in the first week, due to a lack of hospital beds. Among the 549 patients with critical illness, $218(39.7 \%)$ required intensive care with or without mechanical ventilation. 331 patients $(60.3 \%)$ required non-ICU.

300 patients had a magnesium dosage, in mean 5.29 days \pm 5.02 after admission. Basic characteristics of these patients and mean serum concentrations of magnesium, creatinine, selected inflammatory factors, D-dimer, and albumin are presented in table 1.

\section{Prevalence of dysmagnesemia}

As illustrated in figure 1, 144 of 300 (48\%) patients had a magnesemia below $0.75 \mathrm{mmol} / \mathrm{L}$ including 39/300 (13\%) patients with a marked hypomagnesemia $(<0.65 \mathrm{mmol} / \mathrm{L})$. Seventyseven/300 (25.7\%) had a serum magnesium concentration between 0.75 and $0.84 \mathrm{mmol} / \mathrm{L}$, $50 / 300(16.7 \%)$ had a concentration between 0.85 and $0.94 \mathrm{mmol} / \mathrm{L}$. 29/300 (9.6\%) had a serum magnesium concentration equal to or higher than $0.95 \mathrm{mmol} / \mathrm{L}$, including $9(3 \%)$ $\geq 1.05 \mathrm{mmol} / \mathrm{L}$.

\section{Univariate analysis}

As reported in table 2, serum magnesium concentrations were significantly lower in moderate form of Covid-19 ( $\mathrm{p}=0.012)$ and hypomagnesemia prevalence $(<0.75 \mathrm{mmol} / \mathrm{L})$ was significantly higher in this group than in critical form $(p<0.001)$, whereas prevalence of high-level concentrations was significantly increased in critical form ( $\mathrm{p}=0.040$ ) (figure 2).

Serum magnesium concentrations were significantly lower in female than in male $(0.73 \pm$ 0.12 vs $0.80 \pm 0.13 \mathrm{mmol} / \mathrm{L}$ ) whereas the sex ratio increased in severe and critical form $(\mathrm{p}<0.001)$. However, there was no significant interaction between sex ratio and severity form for magnesemia (Anova 2X2) (data not shown).

We analyzed factors associated with hypomagnesemia (below $0.75 \mathrm{mmol} / \mathrm{L}$ ) (table 3) in a univariate analysis. Low magnesemia was significantly and negatively associated with sex-ratio

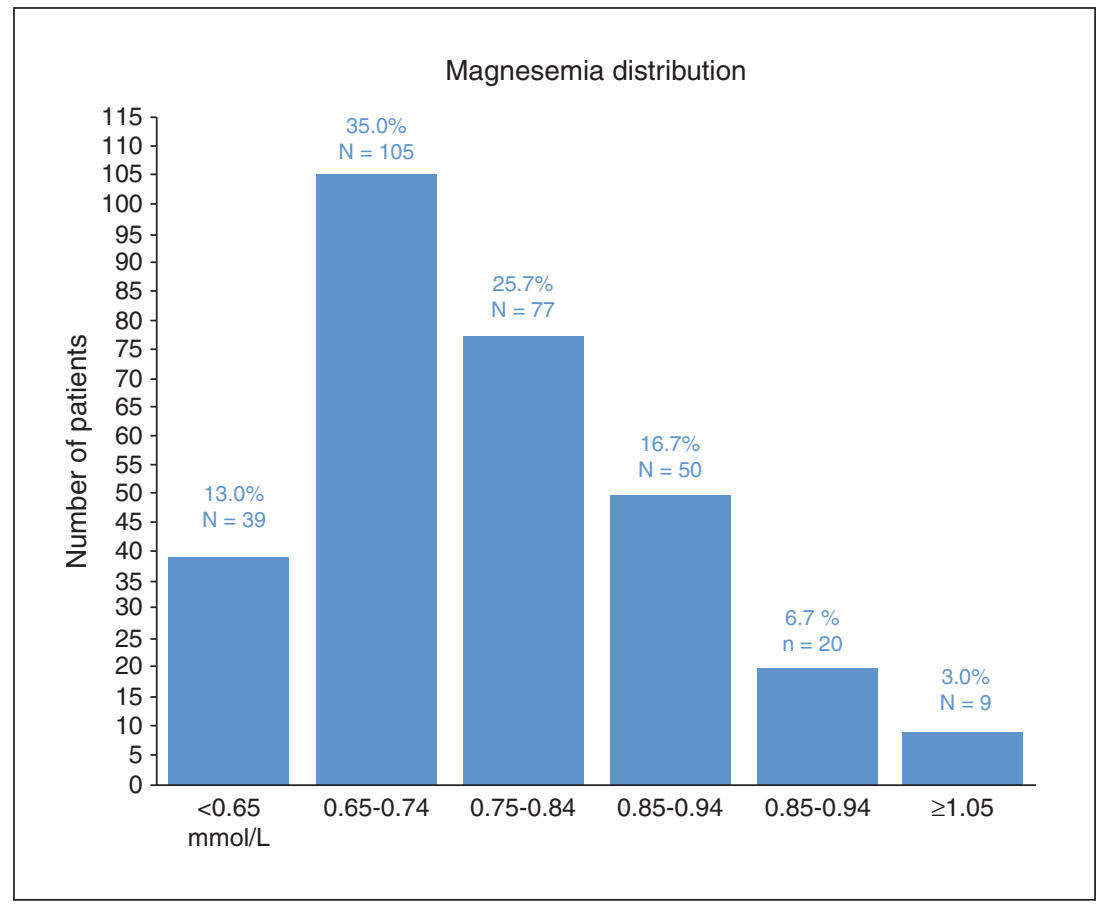

Figure 1. Distribution of serum magnesium concentrations in the cohort of 300 Covid-19 patients. 
Table 2. Demographic and biological parameters according to theCovid-19 severity form.

\begin{tabular}{|c|c|c|c|c|c|c|}
\hline & $\begin{array}{l}\text { Moderate } \\
\text { form }(n=43)\end{array}$ & $\begin{array}{l}\text { Severe form } \\
(\mathrm{n}=108)\end{array}$ & $\begin{array}{l}\text { Critical form } \\
(\mathrm{n}=149)\end{array}$ & $n$ & $\mathbf{p}$ & test \\
\hline Age (years) & $67.4( \pm 21.0)$ & $71.6( \pm 17.9)$ & $63.0( \pm 12.1)$ & 300 & $<0.001$ & Anova \\
\hline Sex ratio $(M / F)$ 183/117 & $16 / 27(37.2 \%)$ & $63 / 45(58.3 \%)$ & $104 / 45(69.8 \%)$ & 300 & $<0.001$ & $\chi^{2}$ \\
\hline Serum magnesium $(\mathrm{mmol} / \mathrm{L})$ & $0.73( \pm 0.02)$ & $0.77( \pm 0.01)$ & $0.79( \pm 0.01)$ & 300 & 0.012 & Anova \\
\hline$<0.75(\mathrm{n}$ and $\%)$ & $29(67.4 \%)$ & $52(48.1 \%)$ & $63(42.3 \%)$ & 300 & 0.040 & $\chi 2$ \\
\hline 0.75 to $0.94(\mathrm{n}$ and $\%)$ & $12(27.9 \%)$ & $48(44.4 \%)$ & $67(45.0 \%)$ & & & \\
\hline$\geq 95 \mathrm{mmol} / \mathrm{L}(\mathrm{n}$ and $\%)$ & $2(4.7 \%)$ & $8(7.4 \%)$ & $19(12.8 \%)$ & & & \\
\hline BMI $\left(\mathbf{k g} / \mathbf{m}^{2}\right)$ & $25.8( \pm 4.40)$ & $27.1( \pm 6.24)$ & $28.9( \pm 6.19)$ & 201 & 0.018 & Anova \\
\hline Creatininemia (5.5-12 mg/L)* & $11.5( \pm 14.4)$ & $11.6( \pm 17.3)$ & $8.53( \pm 6.91)$ & 300 & $<0.01$ & Kruskal-Wallis \\
\hline Albuminemia $(35-52 \mathrm{~g} / \mathrm{L})^{*}$ & $33.5( \pm 4.37)$ & $30.0( \pm 4.81)$ & $26.0( \pm 5.11)$ & 292 & $<0.001$ & Anova \\
\hline D-dimer $(<500 \mu \mathrm{g} / \mathrm{L}) *$ & $1421( \pm 1274)$ & $2054( \pm 1749)$ & $3421( \pm 2818)$ & 188 & $<0.001$ & Kruskal-Wallis \\
\hline Fibrinogen $(2-4 \mathrm{~g} / \mathrm{L})^{*}$ & $4.96( \pm 1.23)$ & $6.66( \pm 1.83)$ & $7.43( \pm 1.78)$ & 235 & $<0.001$ & Kruskal-Wallis \\
\hline $\begin{array}{l}\text { Lymphocytemia }(\mathrm{X} 1000) \\
\left(1000-4000 / \mathrm{mm}^{3}\right)^{*}\end{array}$ & $1.13( \pm 0.545)$ & $0.985( \pm 0.579)$ & $0.891( \pm 0.594)$ & 296 & 0.06 & Anova \\
\hline$\overline{\mathrm{CRP}}(<4 \mathrm{mg} / \mathrm{L}) *$ & $74.0( \pm 63.8)$ & $140( \pm 84.7)$ & $192( \pm 97.6)$ & 264 & $<0.001$ & Anova \\
\hline
\end{tabular}

*Normal reference range

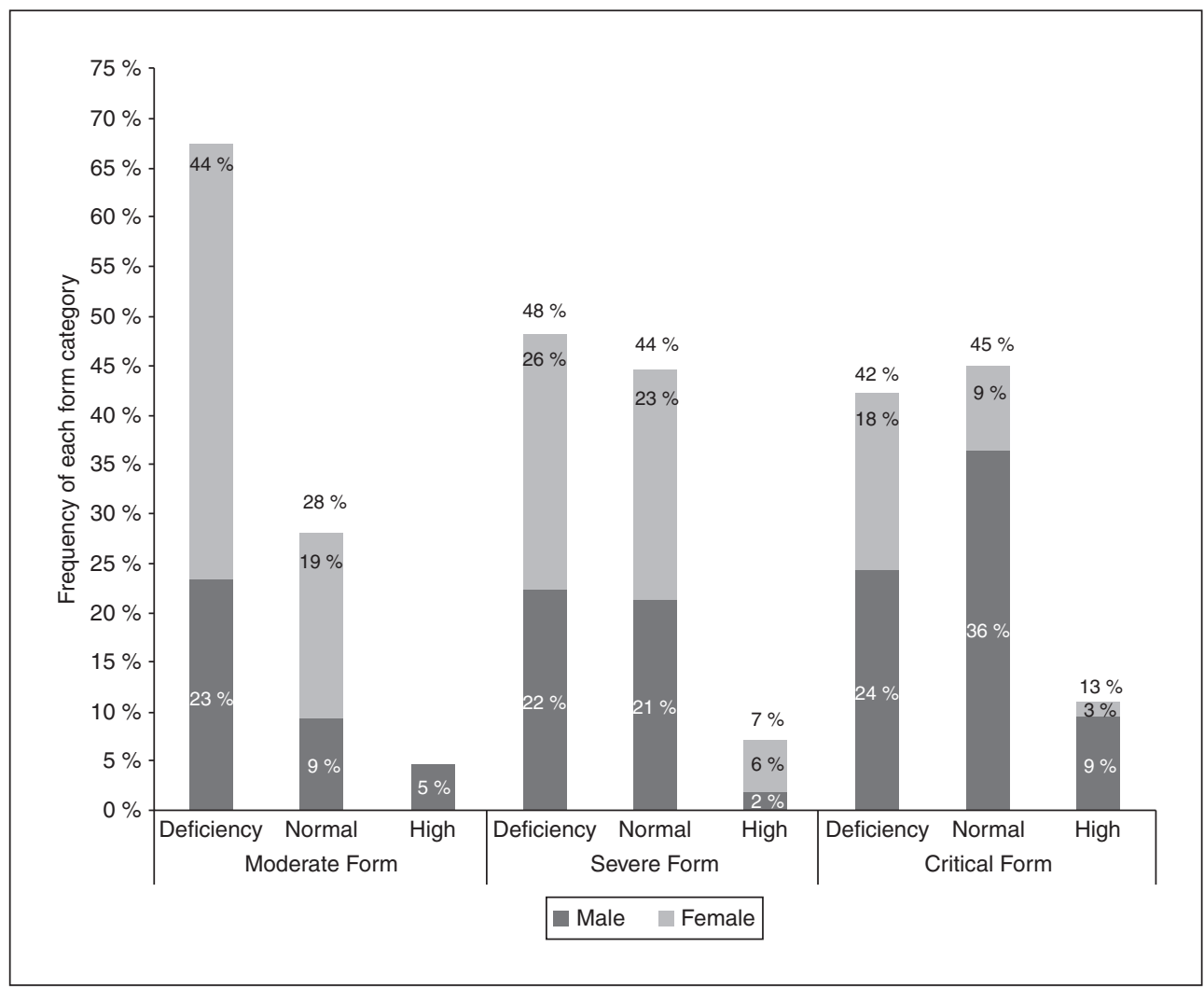

Figure 2. Prevalence of low $(<0.75 \mathrm{mmol} / \mathrm{L}$, normal and high-level $(\geq 0.95 \mathrm{mmol} / \mathrm{L})$ magnesemia according to the severity of Covid-19. $\chi 2 ; p=0.037$. 
Table 3. Bivariate analysis, factors (mean $\pm \mathrm{SD}$ or $\mathrm{n}$ and \%) significantly associated low magnesemia $(<0.75 \mathrm{mmol} / \mathrm{L})$

\begin{tabular}{|c|c|c|c|c|c|c|}
\hline & & $\begin{array}{l}<0.75 \mathrm{mmol} / \mathrm{L} \\
(\mathrm{n}=144)\end{array}$ & $\underset{(\mathrm{n}=156)}{\geq 0.75 \mathrm{mmol} / \mathrm{L}}$ & $\mathbf{n}$ & $\mathbf{p}$ & test \\
\hline Magnesium, mmol/L & & $0.674( \pm 0.068)$ & $0.871( \pm 0.101)$ & 300 & $<0.001$ & Welch \\
\hline \multirow[t]{2}{*}{ Sex, n } & $\underline{\mathrm{M}}$ & $69(49 \%)$ & $113(72 \%)$ & 182 & $<0.001$ & $\chi^{2}$ \\
\hline & $\mathrm{F}$ & $73(51 \%)$ & $43(28 \%)$ & 116 & & \\
\hline \multirow[t]{3}{*}{ Severity } & Moderate & $29(20 \%)$ & $14(9 \%)$ & 43 & 0.015 & $\chi^{2}$ \\
\hline & Severe & $52(36 \%)$ & $56(36 \%)$ & 108 & & \\
\hline & Critical & $63(44 \%)$ & $86(55 \%)$ & 149 & & \\
\hline \multirow[t]{2}{*}{ Nephropathy } & No & $115(80 \%)$ & $139(89 \%)$ & 254 & 0.026 & $\chi 2$ \\
\hline & Yes & $29(20 \%)$ & $17(11 \%)$ & 46 & & \\
\hline \multirow[t]{2}{*}{ Oxygenotherapy } & No & $30(21 \%)$ & $14(9 \%)$ & 44 & $<0.001$ & $\chi^{2}$ \\
\hline & Yes & $114(79 \%)$ & $142(91 \%)$ & 256 & & \\
\hline \multirow[t]{2}{*}{ Critical Care } & No & $82(57 \%)$ & $69(44 \%)$ & 151 & 0.028 & $\chi^{2}$ \\
\hline & Yes & $62(43 \%)$ & $87(56 \%)$ & 149 & & \\
\hline
\end{tabular}

M: male; F: female

$(\mathrm{p}<0.001)$, negatively with Covid-19 infection severity $(\mathrm{p}<0.001)$, presence of nephropathy $(\mathrm{p}=0.026)$, with both oxygenotherapy $(\mathrm{p}<0.01)$ and stay in critical care unit $(\mathrm{p}=0.028)$. $\mathrm{BMI}$, creatininemia $(\mathrm{mg} / \mathrm{L})$, albuminemia $(\mathrm{g} / \mathrm{L})$, D-dimer $(\mu \mathrm{g} / \mathrm{L})$, fibrinogen $(\mathrm{g} / \mathrm{L})$, lymphocytemia $\left(/ \mathrm{mm}^{3}\right)$, CRP $(\mathrm{mg} / \mathrm{L})$, diuretic treatment, and other comorbidities (diabetes mellitus, respiratory failure, etc.) were not significantly associated with hypomagnesemia.

\section{Multivariate analysis}

Logistic regression analysis (table 4) revealed that the strongest and most consistent predictors of low magnesemia were: severity of infection, showing that the severe and critical forms had the lower risk of hypomagnesemia ( $\mathrm{OR}=0.46$, $\mathrm{p}=0.04$ between severe and moderate forms and $\mathrm{OR}=0.39 \mathrm{p}=0.01$ between critical and moderate forms) and nephropathy ( $\mathrm{OR}=1.85)$. Model of logistic regression, including sex ratio, showed that sex ratio was the main predictor of hypomagnesemia.

\section{Discussion}

This transversal study reveals a high prevalence of hypomagnesemia in 300 patients hospitalized for Covid-19. Half of all included patients had a serum magnesium concentration below $0.75 \mathrm{mmol} / \mathrm{L}$ including $13 \%$ which had a marked hypomagnesemia $(<0.65 \mathrm{mmol} / \mathrm{L})$, whereas 1 of 10 patients had high magnesemia ( $\geq 0.95 \mathrm{mmol} / \mathrm{L}$ ).

Multivariate analysis showed that the strongest and most consistent predictors of hypomagnesemia were Covid-19 severity, the moderate form had the higher risk of magnesium deficiency and, secondly, the existence of nephropathy. On the contrary, high-level serum magnesium concentrations were more prevalent in critical form. Women may be at higher risk of deficiency, but the strong interaction between the severity of the infection and the sex-ratio does not allow drawing any conclusion. In fact, sex ratio (male/female) was lower in the moderate group than in severe or critical groups.

Notwithstanding the fact that we observed a higher mean magnesium concentration in ICU, $42 \%$ of these patients had a magnesemia below $0.75 \mathrm{mmol} / \mathrm{L}$ within $10 \%$ below $0.65 \mathrm{mmol} / \mathrm{L}$. These results are in line with other studies showing that hypomagnesemia is commonly seen and frequently overlooked in critically ill patients in ICU [16]. Hypomagnesemia commonly seen in ICU patients appears associated with a poor prognosis [13-15]. In Covid-19 patients, data on magnesemia are scarce and it is difficult to analyze the results due to differences in study protocols. A retrospective study to determine the 
Table 4. Multivariate analysis of hypomagnesemia ( $<0.75 \mathrm{mmol} / \mathrm{L}$ ) (odds ratio) from stepwise logistic regression.

Model 1: analysis of Covid-19 severity, nephropathy, oxygenotherapy, critical care admission

\begin{tabular}{lllll}
\hline & & Odds-Ratio & p & p global \\
\hline Severity & 2 vs 1 & $0.457[0.212 ; 0.951]$ & $\mathbf{0 . 0 4 0}$ & $\mathbf{0 . 0 3 1}$ \\
Nephropathy & 3 vs 1 & $0.386[0.183 ; 0.787]$ & $\mathbf{0 . 0 1 0}$ & - \\
\hline
\end{tabular}

Model 2: analysis of Covid-19 severity, sex, nephropathy, oxygenotherapy, critical care admission

\begin{tabular}{lllll}
\hline & & Odds-Ratio & p & p global \\
\hline Severity & severe vs moderate & $0.545[0.248 ; 1.16]$ & 0.12 & 0.21 \\
& critical vs moderate & $0.520[0.240 ; 1.10]$ & 0.09 & - \\
Sex $($ F vs M) & F vs M & $2.67[1.63 ; 4.42]$ & $<\mathbf{0 . 0 0 1}$ & $<\mathbf{0 . 0 0 1}$ \\
Nephropathy & Yes vs No & $2.12[1.08 ; 4.28]$ & $\mathbf{0 . 0 3 2}$ & $\mathbf{0 . 0 3 2}$ \\
\hline
\end{tabular}

Only factors with a significant association at 0.1 in the bivariate model were entered into the multivariate model

prognostic factors associated with mortality in Covid-19 patients showed significantly lower mean magnesemia on admission to hospital in deceased patients compared to patients discharged at the time of data analysis [21]. This study identified a link between chronic kidney disease and death. In another study [22], the concentration of magnesium was measured in whole blood samples showing a significantly lower magnesium level in severe than in nonsevere Covid-19 patients. Lastly, in a small cohort study [23], hypermagnesemia prevalence was significantly higher in the ICU group than in the outpatient group.

Nevertheless, in hospital and ICU, hypermagnesemia could be the strongest independent predictor of mortality and could be associated with a poor prognosis after community-acquired pneumonia $[10,18,19]$. It commonly occurs due to excessive administration of magnesium salts or magnesium-containing drugs, especially in patients with reduced renal function. However, in the present study, no patient had magnesium supplementation before magnesium measurement. Furthermore, serum magnesium concentration was not correlated to creatininemia or renal function. On the contrary, nephropathy was associated with an increased risk of magnesium deficiency. Hypermagnesemia may be caused by rapid mobilization from soft tissues in patients with sepsis that could explain the positive relationship between serum magnesium concentration and infection severity, as well as inflammatory factor, as CRP $(\mathrm{p}=0.011)$ and fibrinogen $\mathrm{r}=0.236 ; \mathrm{p}=0.028$ ) (data not shown).
In addition, stress conditions can result in an increased loss of magnesium from tissues causing an increase in the concentration of extracellular magnesium [27]. Subsequently, this increase in extracellular magnesium can lead to increased magnesium urinary excretion and deficiency.

Serum magnesium concentration increasing with the severity and degrees of inflammation may be surprising with regard to experimental in vivo and in vitro studies supporting an association between magnesium deficiency and inflammation (recently reviewed by Maier et al. 2020 [5]), this by sustaining inflammation and enhancing the inflammatory response. Crosssectional studies also indicate inverse relationships between magnesium intake, status, and serum IL-6 concentration. Recent systematic reviews of randomized, controlled trials illustrate an inverse relationship of magnesium supplementation with circulating CRP levels, with larger magnitudes of effect among individuals with elevated inflammatory status $[28,29]$. In these studies, the level of inflammation is not commensurate with the levels of inflammation seen during Covid-19. However, hypomagnesemia frequently observed in ICU patients with sepsis is significantly associated with increased need for mechanical ventilation, a prolonged ICU stay, and increased mortality [15].

Our study has several limitations, the most noteworthy being its observational nature. The cutoff chosen in this study could be discussed. In fact, a serum magnesium concentration 
$<0.65 \mathrm{mmol} / \mathrm{L}$ and $<0.75 \mathrm{mmol} / \mathrm{L}$ can serve to identify magnesium deficiency and its severity. We also distinguished the range of 0.75 to 0.85 $\mathrm{mmol} / \mathrm{L}$, often considered within reference values but may reflect chronic latent deficiency. This is particularly interesting for appreciating the longterm effect of this latent low magnesium status on health outcomes [30,31]. The cutoffs used are based on the analysis of the data from literature; however, there is still no consensus on the range values for hypo- and hyper-magnesemia.

We found an important interaction between sex-ratio and severity of Covid-19 infection. It is well known that the severity and mortality of COVID-19 are higher in males than in females. Males are considered the weaker sex in aspects related to endurance and infection control and females elicited stronger immune responses to pathogens. This difference in immune system responses may be a major contributing factor to viral load, disease severity, and mortality [32]. A lower serum magnesium concentration in female was also observed in the large cohort of Mayo-clinic [10] and could be due to confounding factors, such as type and severity of the associated diseases.

This study was furthermore not intended to evaluate the relationship between magnesemia and patient prognosis. Furthermore, at the time of the outbreak of the epidemic patients over 75 years old were not admitted for the ICU, and this generates bias in the distribution between the 3 severity groups. This cohort is heterogeneous and intercorrelation between parameters could alter the analysis.

Lastly, magnesium status assessment was based on serum magnesium concentration. It would be better to measure plasma ionized magnesium, which represents the physiologically active form of magnesium.

\section{Conclusion}

The determinants of dysmagnesemia during this severe infection and its adverse effect on outcome warrant further investigation. Our data nonetheless show the high prevalence of dysmagnesemia that could have an impact on the evolution of Covid-19, not only on inflammation but also on the vascular complications of Covid-19. Therefore, the measurement of serum magnesium should be recommended to detect a dysmagnesemia and ultimately tailor a better treatment strategy to prevent alterations of magnesium homeostasis.

\section{Disclosure}

Financial support: none. Conflict of interest: none.

\section{References}

1. Flatman PW. Magnesium transport across cell membranes. J Membr Biol 1984; 80 : 1-14.

2. Komiya Y, Runnels LW. TRPM channels and magnesium in early embryonic development. Int J Dev Biol 2015; 59 : 281-8.

3. Ohyama T. New Aspects of Magnesium Function: a key regulator in nucleosome self-assembly, chromatin folding and phase separation. Int $J \mathrm{Mol} S c i$ $2019 ; 20: 4232$.

4. de Baaij JH, Hoenderop JG, Bindels RJ. Magnesium in man: implications for health and disease. Physiol Rev 2015; 95 : 1-46.

5. Maier JA, Castiglioni S, Locatelli L, Zocchi M, Mazur A. Magnesium and inflammation: advances and perspectives. Semin Cell Dev Biol in press, available online 18 November 2020. doi.org/ 10.1016/j.semcdb.2020.11.002.

6. Kolisek M, Touyz RM, Romani A, Barbagallo M. Magnesium and other biometals in oxidative medicine and redox biology. Oxid Med Cell Longev 2017; 2017 : 7428796.

7. Mazur A, Maier JAM. Magnesium. In : Caballero B, Finglas P, Toldra F, (eds). Encyclopedia of food and health. $1^{\text {st }}$ ed. AMsterdam: Academic Press, 2015: 587-92.

8. Crosby V, Elin RJ, Twycross R, Mihalyo M, Wilcock A. Magnesium. J Pain Symptom Manag 2013; 45 : 137-44.

9. Hansen BA, Bruserud O. Hypomagnesemia in critically ill patients. J Intensive Care 2018; 6 : 21.

10. Cheungpasitporn W, Thongprayoon C, Qian Q. Dysmagnesemia in hospitalized patients: prevalence and prognostic importance. Mayo Clin Proc 2015; 90 : 1001-10.

11. Malinowska J, Malecka M, Ciepiela O. Variations in magnesium concentration are associated with increased mortality: study in an unselected population of hospitalized patients. Nutrients 2020; 12 : 1836.

12. Catalano ABF, Chilà D, Loddo $\mathrm{S}$, et al. Rates of hypomagnesemia and hypermagnesemia in medical settings. Magnes Res 2021; in press. 
13. Ryzen E, Wagers PW, Singer FR, Rude RK. Magnesium deficiency in a medical ICU population. Crit Care Med 1985; 13 : 19-21.

14. Escuela MP, Guerra M, Anon JM, et al. Total and ionized serum magnesium in critically ill patients. Intensive Care Med 2005; 31 : 151-6.

15. Velissaris D, Karamouzos V, Pierrakos C, Aretha D, Karanikolas M. Hypomagnesemia in critically ill sepsis patients. J Clin Med Res 2015; 7 : 911-8.

16. Jiang P, Lv Q, Lai T, Xu F. Does hypomagnesemia impact on the outcome of patients admitted to the intensive care unit? A systematic review and metaanalysis. Shock 2017; 47 : 288-95.

17. Upala S, Jaruvongvanich V, Wijarnpreecha K, Sanguankeo A. Hypomagnesemia and mortality in patients admitted to intensive care unit: a systematic review and meta-analysis. QJM 2016; 109 : 453-9.

18. Laupland KB, Tabah A, Jacobs N, Ramanan M. Determinants of serum magnesium abnormalities and outcome among admissions to the intensive care unit. Anaesth Crit Care Pain Med 2020; 39 : 793-7.

19. Nasser R, Naffaa ME, Mashiach T, Azzam ZS, Braun E. The association between serum magnesium levels and community-acquired pneumonia 30-day mortality. BMC Infect Dis 2018; 18 : 698.

20. Iotti S, Wolf F, Mazur A, Maier JA. The COVID-19 pandemic: is there a role for magnesium? Hypotheses and perspectives. Magnes Res 2020; 33 : 21-7.

21. Alamdari NM, Afaghi S, Rahimi FS, et al. Mortality risk factors among hospitalized covid-19 patients in a major referral center in iran. Tohoku $J$ Exp Med 2020; 252 : 73-84.

22. Zeng HL, Yang Q, Yuan P, Wang X, Cheng L. Associations of blood essential and toxic metal(loid) $\mathrm{s}$ with both disease severity and mortality in patients with COVID-19: a retrospective study. Research Square 2020;
23. Sarvazad H, Cahngaripour SH, Eskandari Roozbahani N, Izadi B. Evaluation of electrolyte status of sodium, potassium and magnesium, and fasting blood sugar at the initial admission of individuals with COVID-19 without underlying disease in Golestan Hospital, Kermanshah. New Microbes New Infect 2020; 38 : 100807.

24. Cheng MP, Papenburg J, Desjardins M, et al. Diagnostic testing for severe acute respiratory syndrome-related coronavirus 2 : a narrative review. Ann Intern Med 2020; 172 : 726-34.

25. WHO. Clinical management of COVID-19: interim guidance. 2020. Available from: WHO/2019-nCoV/ clinical/2020.5. May 2020.

26. Arnaud MJ. Update on the assessment of magnesium status. Br J Nutr 2008; 99(Suppl 3):S24-36.

27. Pickering G, Mazur A, Trousselard M, et al. Magnesium status and stress: the vicious circle concept revisited. Nutrients 2020; 12 : 3672.

28. Mazidi M, Rezaie P, Banach M. Effect of magnesium supplements on serum C-reactive protein: a systematic review and meta-analysis. Arch Med Sci 2018; 14 : 707-16.

29. Simental-Mendia LE, Sahebkar A, RodriguezMoran M, Zambrano-Galvan G, Guerrero-Romero F. Effect of magnesium supplementation on plasma c-reactive protein concentrations: a systematic review and meta-analysis of randomized controlled trials. Curr Pharm Des 2017; 23 : 4678-86.

30. Elin RJ. Assessment of magnesium status for diagnosis and therapy. Magnes Res 2010; 23 : S194-8.

31. Costello RB, Elin RJ, Rosanoff A, et al. Perspective: the case for an evidence-based reference interval for serum magnesium: the time has come. $A d v$ Nutr 2016; 7 : 977-93.

32. Pradhan A, Olsson PE. Sex differences in severity and mortality from COVID-19: are males more vulnerable? Biol Sex Differ 2020; 11 : 53. 